\title{
Bar orientation in operant escape training'
}

GARRY A. FLINT, ${ }^{2}$ INDIANA UNIVERSITY, Bloomington, Indiana 47401

In operant escape training a rat is usually required to deflect a bar in a downward direction to terminate shock for a short interval of time. In the study described here, eight rats were conditioned with the bar mechanism modified to require a sideways deflection. The acquisition of escape responding with the bar in the modified position was inferior to the responding typically observed with the bar in the usual position. Sequences of successful escape responding were observed when the bar required a sideways deflection, but the response-reinforcement contingency was not adequate to maintain escape behavior.

In escape training, rats deflect a bar to terminate shock. In previous discussions of the escape response (Dinsmoor, 1968; Dinsmoor, Hughes, \& Matsuoka, 1958; Dinsmoor \& Campbell, 1956; Migler, 1963) it was assumed implicitly that the bar press was an operant response that was strengthened by the shock termination. An experiment by Flint (1968) suggested that the bar operation, viz, the downward (vertical) deflection, was a requirement for rapid acquisition of the escape response. When the bar operation results in a downward deflection, the tendency to perseverate following the shock termination (Kheen, 1968; Flint, 1968) leaves the rat either deflecting the bar or in the near vicinity. The purpose of the present experiment was to determine whether or not escape responding could be easily conditioned when the rat was required to deflect a bar in a sideways (horizontal) direction.

When the bar is in a position requiring a sideways deflection, there are more opportunities for escape response topographies that are different from the pressing response obtained with the bar oriented in the usual position. A relatively low rate of acquisition with these topographies would indicate that the pattern of escape responding in the normal condition is dependent upon the bar position. Further, if bar holding or escape responding were under the control of shock duration or shock termination to the extent that is implied by previous escape training research, then escape behavior occurring with the sideways response requirement should be maintained throughout the session.

\section{METHOD}

The Ss were eight naive, 180 - to 210-day-old, male Sprague-Dawley rats randomly assigned to the various conditions and shaved within $2 \mathrm{~h}$ of the experimental session.

The Ss were conditioned, in the absence of light, in a chamber $6 \times 8 \times 7$ in. high (see Flint, 1968, for details). A plastic door covered with screenwire allowed full view of the Ss when illuminated by a GE 1829 lamp located in the top left corner of the bar panel. The floor consisted of five $1 / 2$-in. diam bars, $3 / 4$ in. apart, running the length of the enclosure. Input to the shock scrambler was $2 \mathrm{~mA}$ ac passing through a $50 \mathrm{~K} \mathrm{ohm} \mathrm{resistor.} \mathrm{A}$ modified Lehigh Valley Shock Scrambler provided about 10 polarity changes per grid per second. The response bar, $1 \frac{1}{2} \mathrm{in}$. wide $x 3 / 8$ in. thick, extended $1 / 2$ in. into the chamber and was mounted $3 \frac{1}{2}$ in. above the grid in a panel that allowed the bar to be rotated into a position where it required a sideways deflection. A force requirement of $20 \mathrm{~g}$ was electromagnetically reduced to 3 to $5 \mathrm{~g}$ by the end of the 1/16-in. deflection. A microswitch closure occurring in the center of the deflection indicated a change in bar position.
The escape training schedule was programmed by relay circuitry and ATC timers. Two bar contingencies were used. One required the rat to press the bar to terminate shock so that when the bar was in the deflected position at shock onset, a release followed by a press was required. The other contingency required the rat to release the bar to terminate shock; when the bar was in the released position at shock onset, then a press followed by a release was required. White noise feedback was provided for $50 \mathrm{msec}$ following the appropriate movement of the bar. An escape response terminated continuous shock for $15 \mathrm{sec}$, after which the shock was again initiated.

The assignment to boxes and to counterclockwise and clockwise rotation of the bar were counterbalanced for the press and release groups, and the entire experiment was carried out in 2 days. On Day 1 , the $S s$ were given $2 \mathrm{~h}$ of escape training with the bar in the vertical position requiring sideways deflection. The experimental enclosures were inspected every $30 \mathrm{~min}$ by briefly illuminating the enclosure with the houselight to determine whether the grids were shorted. The topography of the response was usually noted at about $10 \mathrm{~min}$ before the end of the session. On the following day, the Ss were run with the bar in the standard horizontal position for about $1 \mathrm{~h}$ or until the $\mathrm{S}$ made 100 escape responses.

\section{RESULTS}

The results are shown in Fig. 1. On Day 1, both the press and release groups were required to deflect the bar in a sideways (horizontal) direction to terminate the shock. The records show that escape responding was not easily acquired under these conditions. Most Ss executed a series of escape responses long enough to have been maintained for the duration of the session had the bar been oriented to require the usual downward deflection (e.g., see Day 2). However, even after the fairly long sequences of escape responding (see Point a), the responding usually terminated abruptly.

Only two of the rats appeared to be responding in an efficient

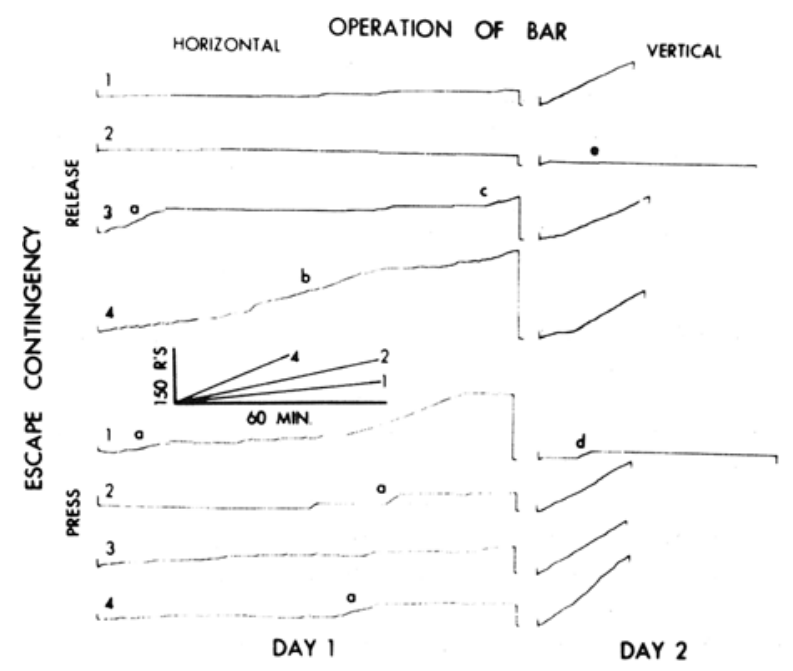

Fig. 1. Cumulative records of the acquisition of escape responding for both the press and release procedures. The requirement for shock termination on Day 1 was the horizontal deflection of the bar, and on Day 2 the vertical deflection of the bar. 
manner. At Point b, release rat No. 4, poised with the left paw on the top end of the bar, apparently swatted the bar with its right paw at shock onset. Later observation revealed that this rat was making less efficient responses by fanning the air in the region of the bar, which sometimes deflected the bar and terminated the shock. The other rat responding for most of the session was the press rat No. 1. Because the light disrupted ongoing behavior, press rat No. 1 was not checked at $90 \mathrm{~min}$. At $110 \mathrm{~min}$, this animal was receiving shock while attempting to escape the stimulus by lying on its back. At Point c, rat No. 3 of the release group was observed to be terminating the shock with its rear flank. Several other positions used to produce shock termination were: lying horizontally under the bar with the hind end humped up touching the bar, deflecting the bar with the left fore shoulder, and slouching on the grid and the bar panel between the bar and the wall with its hind feet and tail extending into the air. In the latter case, the movement of the forearms at the onset of shock produced the bar deflection.

These escape behaviors all resulted in sequences of escape responding that later terminated. The varied sequences suggest a fixed topography at the termination of shock, i.e., response perseveration. Since these response patterns failed to continue, however, response perseveration does not appear to be the only requirement for continued escape responding. These particular escape responses were not maintained by the existing reinforcing contingencies, which suggests that either the particular response topography or the usual bar position in the normal escape training situation facilitates bar holding and escape responding.

On Day 2, the rats were given escape training with the bar in the normal position. One $S$ in each group failed to learn. Release rat No. 2 approached the light during observation and inadvertently pressed the bar at Point e. On later inspection, the rat was observed to be receiving shock while attempting to avoid shock by dangling its legs through the floor grids. Press rat No. 1 initiated the sequence of responses at $d$, following an inspection of the grids. For these two animals, competing behavior acquired on the previous day may have suppressed the more adaptive behavior on Day 2. In general, conditioning seems to be difficult following a period of exposure to continued shock (Dinsmoor \& Campbell, 1956).

\section{DISCUSSION}

The results show that escape responding is more difficult to obtain when the response requirement is a sideways deflection of the bar. The occasional occurrence of sequences of relatively successful escape responding with the sideways deflection suggests some control of the reinforcement contingency between the response resulting in the switch closure and, hence, the shock termination. When the escape response is not easily performed, as in the case of downward bar press with a paw, then the response is not easily maintained.

The awkward or inefficient behaviors producing sequences of escape responses (see Day 1, Fig. 1) suggest that the initial bar operation is an inadvertent event that results from the haphazard behavior occurring in the presence of shock. The maintenance of these awkward responses or positions is primarily a function of response perseveration following shock termination. In escape conditioning, rats readily assume positions at the termination of shock that often extend throughout the intershock interval. Since operant behavior in shock situations is greatly confounded by elicited behavior, the perseveration following shock termination is adaptive when shock termination is contingent upon behavior occurring in a specific location in the enclosure. Thus, stationary behavior or "freezing" (Bolles \& McGillis, 1968) is probably the most adaptive response possible following the termination of a noxious stimulus. For example, if the rat freezes with the bar deflected, an elicited response at shock onset may result in rapid termination of the stimulus (Migler, 1963; Flint, 1968). In this case, freezing is the shaping of behavior that maximizes the occurrence of the inadvertent bar deflection by elicited behavior.

Bolles and MoGillis (1968) propose that the "short-latency mode of responding is shaped up by the differential punishment of all other behavior, rather than by the escape contingency itself." This explanation seems untenable since the presence of shock is independent of the behavior. Shock in this situation functions as an eliciting stimulus early in conditioning to increase overall activity, and as a discriminative stimulus later in conditioning (Migler, 1963), when operant components of escape responding become more strongly conditioned. It is proposed here that the short latency responding observed in escape training is primarily a function of the relationship between an elicited response at shock onset, the bar position, and the response topography prior to stimulation. Further, behavior in the presence of shock gradually shifts to the bar region, resulting in shorter escape latencies. It seems most operational to attribute this response shaping both to the differential reinforcement of the shockelicited behavior by shock termination and to the perseveration of behavior in the region of the bar, rather than to punishment of behavior away from the bar.

\section{REFERENCES}

BOLLES, R. C., \& MoGILLIS, D. B. The non-operant nature of the bar-press escape response. Psychonomic Science, 1968, 11, 261-262.

DINSMOOR, J. A. Escape from shock as a conditioning technique. In M. R. Jones (Ed.), Miami symposium on the prediction of behavior, 1967: Aversive stimulation. Coral Gables: University of Miami Press, 1968. Pp. 33-75.

DINSMOOR, J. A., \& CAMPBELL, S. L. Escape-from-shock training following exposure to inescapable shock. Psychological Reports, 1956, 2, 43-49.

DINSMOOR, J. A., \& CAMPBELL, S. L. Level of current and time between sessions as factors in "adaptation" to shock. Psychological Reports, 1956, 2, 441-444.

DINSMOOR, J. A., HUGHES, L. H., \& MATSUOKA, Y. Escape-fromshock training in a free response situation. American Journal of Psychology, 1958, 71, 325-337.

FLINT, G. A. Unconditioned responses and bar holding in escape training. Doctoral dissertation, Indiana University, 1968.

KHEEN, J. D. Is bar-holding with negative reinforcement preparative or perseverative? Journal of the Experimental Analysis of Behavior, 1967, $10,461-465$.

MIGLER, B. Barholding during escape conditioning. Journal of the Experimental Analysis of Behavior, 1963, 6, 65-72.

\section{NOTES}

1. This paper is based in part on a thesis presented to the Graduate School, Indiana University, in partial fulfillment of the requirements for the $\mathrm{PhD}$ degree. The research was carried on at Indiana University and was supported by Research Grant MH 10474 from the National Institute of Mental Health awarded to Dr. J. A. Dinsmoor, a grant from the Indiana University Graduate School, and a generous grant of computer time from the Indiana University Research Computing Center. Preparation of this manuscript was supported by USPHS Training Grant No. MH 7082. Many thanks are due Dr. J. A. Dinsmoor for his helpful advice and assistance.

2. Now at Langley Porter Neuropsychiatric Institute, 401 Parnassus Avenue, San Francisco, California 94122. 